\title{
Current Situation of Highway Daily Maintenance Management in Beijing
}

\author{
Feng Ming PAN , Bao Lin ZHU , Jia HUI, Rui Nan JIANG, Tong WANG
}

China Academy of Transportation Sciences, Beijing 100029, China

\begin{abstract}
Combined with the industry property, characteristics and management needs of highway maintenance project in Beijing, through investigation and research of the highway daily maintenance management, the present situation of highway repair and maintenance is expounded from the aspects such as the determination of maintenance funds and plan, maintenance management mode, and so on. Then in order to explore the new mechanisms for market management of highway maintenance, the advantages and disadvantages of highway maintenance and minor repairment of Beijing are analyzed.
\end{abstract}

Keywords: highway; maintenance management; maintenance and minor repairment; operating model

\section{INTRODUCTION}

In recent years, China's road construction has been developed rapidly as increasing investment in transportation infrastructure. By 2013 , it has reached $6417 \mathrm{~km}$ that road maintenance mileage of county level and above in Beijing. Rapid growth of highway construction obtains economic development and social benefits. The fast, safe and comfort features of road provide quality services for drivers and passengers, and earn widespread admiration. As society progresses, people's requirements for road is not only fast, safe, comfortable, but also green traffic environment of "smooth, clean, green and beautiful".

In order to improve the urban environment, this article synthetically considered factors of industry nature, characteristics and management needs of highway maintenance in Beijing, carried out road daily maintenance management and research, and explored new mechanisms of market management of road maintenance.

\section{OVERVIEW OF BEIJING ROAD MINOR REPAIRMENT AND MAINTENANCE}

By the end of 2012, Beijing's traffic capacity and accessibility has significantly increased. Total mileage of Beijing highways network has reached $21,492 \mathrm{~km}$; highways network density of the city has increased from $87 \mathrm{~km} / 100 \mathrm{~km} 2$ by the end of 2005 to $131 \mathrm{~km} / 100 \mathrm{~km} 2$. According to administration social estate, national expressway is $561 \mathrm{~km}$, national highway is $754 \mathrm{~km}$, city road is 2222 $\mathrm{km}$, county road is $3838 \mathrm{~km}$, country road is $8067 \mathrm{~km}$, village road is $5563 \mathrm{~km}$, and specified road is $487 \mathrm{~km}$. According to technology classification, expressway is $922 \mathrm{~km}$, one-level road is $1118 \mathrm{~km}$, two-level is $3283 \mathrm{~km}$, three-level road is $3641 \mathrm{~km}$, four-level road is 
$12335 \mathrm{~km}$, and substandard road is $193 \mathrm{~km}$. The proportion of secondary road and above grade in national and urban highway is $97.03 \%$.

Beijing Municipal Roadway Administration Bureau takes charge of the maintenance management of the basic transportation facilities including highways, city roads, county road and etc in Beijing. Currently, the maintenance mileage of Beijing county road and above grade has reached $6417 \mathrm{~km}$, including national expressway $628 \mathrm{~km}$, urban road $1896 \mathrm{~km}$, county road $3893 \mathrm{~km}$.

The major and intermediate maintenance technology (including preventive maintenance) mileage of average annual program implementation accounts for no less than 17 percent of the total mileage of national, city, county trunk highway. The Pavement Performance Index (PQI value) of national, city, county trunk highway remains above 90 ; that is to say, the value remains above 90 per year, and the mileage of excellent road remained above 90\%. The Pavement Performance Index (PQI value) of county road remains above 88 ; that is to say, the value remains above 88 per year, and the mileage of excellent road remained above $90 \%$. The transformation rate of existing dangerous bridge was $100 \%$ between national, city trunk highway and county road, and the treatment rate of the newly found dangerous bridge in those years was $100 \%$. The proportion of national, city trunk highway I, II bridge was $94.7 \%$, and the proportion of county road I, II bridge was $93.7 \%$.

\subsection{Determination of maintenance funds and plan}

(1) The allocation of highway maintenance and minor repairment funding is based on the structural features of each county's road network. According to the highway administration social estate, road width, traffic volume, date of construction, and geographical conditions (mountain/plain), after analyzing scientifically that the allocation of highway maintenance and minor repairment funds, highway maintenance and minor repairment funds have been allocated to 10 road sub-bureau by the administrative region considering local needs. The sub-bureaus make the secondary investment decomposition plan to allocate the funds to each route or road based on current road network service condition.

(2) Overhaul project investment plan is determined based on data collection, the road condition evaluation, and the decision optimization of fast road condition monitoring data. Generally the road sub-bureau of each county prepares and reports preliminary construction plans based on the evaluation results of the detection data analysis. Maintenance engineering department of each sub-bureau organizes experts to discuss and determine the plans. Then, according to the engineering project, each sub-bureau makes preliminary design based on the plans and reports to the roadway administration bureau for approval. The roadway administration bureau authorizes consulting firm to audit the project budget, and approve the preliminary engineering design and project budget. Planning management department of the bureau prepares annual investment plan in highway construction. The plan is audited by the transportation committee and reported to the municipal public finance for approval. After the municipal finance bureau for approval, the municipal roadway administration bureau let the branch and direct subordinate unit to execute.

\subsection{Operation mode of maintenance management}

(1) The major and intermediate maintenance project management has the full realization of market-oriented operation, open the way for the country to take a tender to select maintenance engineering construction enterprise and project management company. 10 suburban counties road branch as the main construction 
unit project, according the Municipal Transportation Commission Road Council, approved the preliminary design of the project budget and tissue engineering project bidding. Under project implementation, each highway branch as the main manager, was responsible for project progress, quality, funds, and management of completion. With the supervision of the municipal roadway administration bureau, project payment was paied according the maintenance progress and test results of quality.

(2) It is adopted that mode of contracting out to manage highway maintenance and minor repairment. The contract is mainly awarded to a maintenance company in Beijing. In this mode, each sub-bureau signs contracts with the company's regional center. Those contracts clearly define maintenance operation standard, maintenance quality standard, maintenance operation frequency, and maintenance engineering quantity list etc. Projects of 100 million yuan and above take public bidding to determine the maintenance enterprises.

(3) In the maintenance quality supervision, the highway bureau directly commissioned with corresponding company of supervision qualification, which was responsible for the quality supervision of highway maintenance and minor repairment. Each highway bureau implemented process supervision for maintenance project, carried out compliance checks in accordance with the management approach. In general, the performance evaluation and assessment were carried out according to the monthly payment. Highway emergency management is a part of daily maintenance and management content, and is entrusted to undertake by conservation work units, while signing the contract.

The working relationships among highway branch, maintenance supervision, and maintenance companies are shown in Figure 1.

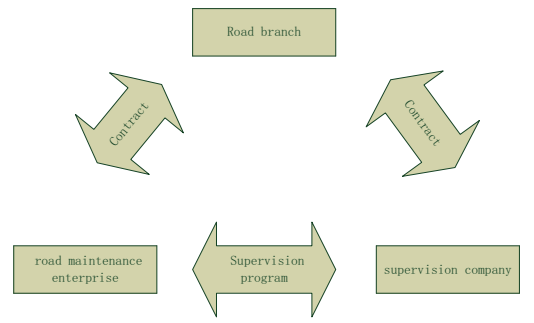

Figure 1 Highway maintenance management operation mode

\section{ADVANTAGES OF BEIJING HIGHWAY MAINTENANCE AND MINOR REPAIRMENT}

\section{(1) Maintenance System}

The strict rules of work are carried out, which makes division of responsibilities, work relations and work tasks clear and definite.

\section{(2) Maintenance Management}

Government departments have been streamlined. Then the maintenance vocational work with specifications and standards can be entrusted to the maintenance company and other social institutions to implement. The government improves management efficiency through supervision and restrictive contracts.

\section{INADEQUACIES OF BEIJING HIGHWAY MAINTENANCE AND MINOR REPAIRMENT}

\subsection{Maintenance System}

At present, for the maintenance system, it is separated of management and maintenance. However, effective competition mechanism has not been introduced in highway maintenance and minor repairmen because the maintenance enterprise in this market is monopolistic. This situation lead directly to lack of investment in road maintenance funds, inadequacies of technological innovation, and imperfections of enterprise management system. Therefore, it is affected that the improvement of the maintenance technology level and the innovation 
of management mechanism. So far, there is still a lack of effective market access mechanism, and competition can't really be introduced in the field of maintenance.

\subsection{Operational Mechanism}

Beijing traffic department implemented separation of administration from management in 2003. A maintenance company is an independent legal entity, that is to say, personnel, administration, finance and other aspects are full independence. This model is in line with the development trend of market economy. At present, maintenance and minor repairment has not been fully realized market-oriented management. There is a lot of work needs to be done to form conservation management mechanism in line with actual needs of this city.

\subsection{New Demands of Urbanization Road}

Beijing has entered a new stage of the development of the medium developed cities to the world city. The city has been expanding. The standard of living is constantly improving. With the rapid increases in the level of motorization, public's attention to the road service and demand is also getting higher and higher. The public has higher expectations of safe and smooth traffic so comprehensive service ability of highway infrastructures is facing a higher demand.

High-speed economic development of Beijing, promotes the city's management level, as well as the overall environmental requirements of the highway. This demands greater accountability from maintenance work since the highway and road-side facilities environment is an important part of the city. Virescence of separators, road shoulders and slopes is the first impression of the urban environment.

(2) Requirements of Improvement of Security Facilities

As urbanization processing, the road facilities need to be improved in accordance with the standards of urban roads. Street lamps, fences, traffic lights, warning signs and other safety facilities need to be upgraded.

(3) Requirements of Improvement of service quality

Integrity traffic, complete signs and marking, perfect auxiliary facilities, fine green and clean road are the keys to improve the quality of highway service. In addition to the daily maintenance work, the timely detection and treatment of emergencies on the highway is one of the important means to enhance the level of highway maintenance. Because of heavy traffic, large amount of ancillary facilities, and complex traffic composition, city highway needs to carry out maintenance according to the city standard, in order to guarantee the quality of service.

\subsection{Funding}

With the increasing public demand, the Beijing road maintenance management tasks become more difficult, and more and more money are demanded. After the fuel oil tax reformation, the ordinary highway construction and maintenance are facing huge financial pressure. During "Twelve-Five", the contradiction of maintenance funds shortfall becomes more and more obvious. Currently, maintenance funding problems are mainly embodied in the following aspects:

(1) Lack of maintenance cost accounting basis. In the current management system, maintenance quotas are not introduced, and maintenance cost accounting and maintenance costs to the financial application are baseless.

(2) Lack of the investment of maintenance science and technology. Due to the lack of investment in science and technology, which directly leads to the managing authorities and the maintenance units are lack of enthusiasm for the maintenance of new technologies, research and development of new material. Related research and development are seriously lagged behind, 
which leads to lack of conservation technology content and low curing efficiency.

(3) Along with the quickening of the urbanization process, the new demand of highway maintenance is put forward. It will inevitably lead to increasing costs of the road cleaning, painting, paint, loss repair, replacement, personnel protection and other daily maintenance.

\subsection{Maintenance Work}

Since the separation between government and enterprises, highway maintenance in Beijing has a great leap and highway maintenance technical level was also rising. However, a survey shows that there aren't maintenance specifications in current contract, and the evaluation rules are not comprehensive, detailed, and uniform standard. These are not good for maintenance system standardization and refinement of management. The problems seriously affect the improvement of the level of highway maintenance. That mainly shown in following aspects:

(1) The detailed degree is insufficient. In the maintenance work, there is no specific requirement for flatness in pavement maintenance. That doesn't meet the idea of detailed management and detailed maintenance.

(2) The degree of standardization is insufficient. This mainly incarnates that the maintenance work site is informal, and the safety level of maintenance work is inadequate.

(3) The special mechanic is insufficient in maintenance operation. The main reasons for this problem are as following,

1. The maintenance workers' cultural level is low.
2. The investment in machinery and equipment is insufficient.

3. The special machinery and equipment are lack of development and application.

(4) The amount and pertinency of maintenance squad material reserves are insufficient. This increases the cost of material reserves, and reduces the efficiency of maintenance operations.

\section{CONCLUSION}

In recent years, highway maintenance in Beijing has developed enormously. The process of market-oriented operation and fine management has been pushing forward. However, there are some problems in practice. Combined with Beijing regional practical situation of development, the competitive market mechanism has been introduced appropriately. In order to satisfy the masses' growing transportation needs, and the new demands of highway maintenance management under the condition of urbanization, through tender document, management requirements have been paid much attention to, and transportation capability and level of transportation service have been tried hard to increase.

\section{References}

[1] Zhao Qin. Problems and solutions of road maintenance management $[\mathrm{J}]$. Architectural Knowledge, 2013 (B12): 213.

[2] Jiang Bin. Brief Talk on Highway Maintenance Management $[\mathrm{J}]$. China New Technologies and Products, 2013 (23): 146.

[3] Zhang Ruizhuo, Yang Jin. Current Situation and Development Direction of Expressway Maintenance Management [J]. East China Highway, 2013 (5), 3 5. 
[4] Lin Wencheng, Song Yanda. The Research on Highway Maintenance Management [J]. China Science \& Technology Panorama Magazine, 2013 (22): 140.

[5] Hu Fanjie, Ma Hongli. Discussion on Management of Administration mechanism and Improvement on Highway Maintenance. Journal of Henan Science and Technology, 2013 (11): 143. 